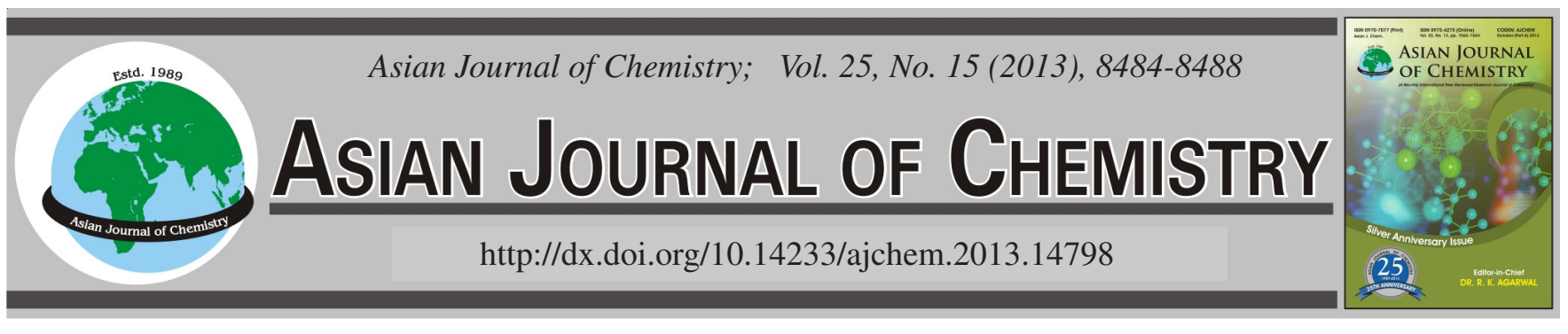

\title{
Characteristics of Ancient Mortars and Plasters from the Archaeological Site of Akbari-Serai (Pakistan)
}

\author{
S. Gulzar ${ }^{1, *}$, M.N. Chaudhri ${ }^{1}$, J.P. Burg ${ }^{2}$ and S.A. SAEED ${ }^{3}$
}

${ }^{1}$ College of Earth and Environmental Sciences, University of the Punjab, Lahore, Pakistan

${ }^{2}$ Swiss Federal Institute of Technology Zurich, Geological Institute, NO E 67, Sonneggstrasse 5, CH-8092 Zurich, Switzerland

${ }^{3}$ Architect/CEO, Sohail Saeed and Associates Consulting Architects \& Engineers, 66/A, Babar Block, New Garden Town, Lahore 54600, Pakistan

*Corresponding author: Fax: +92 42 35831866; Tel: +92 3009422811; E-mail: saimagulzar@yahoo.com

The 17th century Mughal mortar and plaster samples were collected from Akbari-Serai (Shahdara) in the city of Lahore, Pakistan. The samples were studied employing chemical, mineralogical and micro-structural techniques consisting of X-ray diffraction, X-ray fluorescence, optical microscopy and scanning electron microscopy. The mortars and plasters were based on calcitic lime binder prepared by the calcinations of locally available lime nodules $\left(\right.$ kankar- $\left.\mathrm{CaCO}_{3}\right)$ from soil horizon, differing in the type and proportion of aggregates used, including crushed bricks, broken kankar pieces, brick kiln furnace slag and a small fraction of siliceous sand. The results showed varying binder aggregate ratio and also indicated different chemical composition according to the function of mortars and plasters in the masonry unit.

Key Words: Mortars, Plasters, X-Ray fluorescence, SEM-EDS, X-Ray diffraction, Optical microscopy.

\section{INTRODUCTION}

Restoration and conservation of built heritage requires the use of compatible materials similar to or prepared by the reproduction of the historic materials and construction technology. The complete characterization of the originally employed historic materials that also provides information of their manufacturing processes can lead to the success of the restoration process ${ }^{1,2}$. The accelerated deterioration of built heritage in Pakistan is mainly attributed to the lack of information about the historic materials, technology and diagnostic procedures $^{3}$.

The Akbari Serai was built in the first half of the 17th century and presents unique Mughal geometrical style in red sandstone with white marble inlay ${ }^{4}$. There are two gateways to the north and south sides of the Akbari Serai with entrance gate which leads to the Jahangir tomb to the east side and a mosque towards the west in a perfect symmetry and harmony. Akbari Serai is laid around a rectangular landscaped court which is surrounded by the rooms along the perimeter. There are 36 rooms along the north and south walls each where as the east and west walls have 48 rooms on each side. Additionally, there are four corner rooms at the crossing ends. These rooms are made accessible through a raised walkway where common passage and a verandah run all along the façade. Each room is square in shape, surrounded by thick masonry walls which are entered through a verandah. The common passage and verandah have been interacting devised as a transition space. A door opening has been provided at the axial center of the rooms where as the enclosing walls of verandah are punctuated with niches. A four feet wide niche has also been provided in the wall opposite to the door opening. The drain channel 9 inches wide for the purpose of water disposal runs through the outer edge of the passage. Akbari Serai exhibits true symmetry, with geometrical perfection from large scale to the minor detailing which has been the salient feature of the Mughal buildings.

The main objective of this study is to obtain historic materials (mortars and plasters) information useful for the future prevention of decay mechanisms and to formulate appropriate compatible repair mortars and plasters.

\section{EXPERIMENTAL}

Sampling methodology: The sampling locations were identified on different architectural elements in order to collect samples representative of the historic materials construction according to the international standards ${ }^{5,6}$. Samples 1-2 were collected from the rest rooms (Fig. 1a) surrounding the courtyard, samples 3-4 from the entrance gateway (Fig. 1b) to the Serai and samples 5-7 from the corridors (Fig. 1c). In particular, sample 1 and 2 were collected from the masonry core used as filler with bricks. The collected samples 3 and 4 were the mortar 


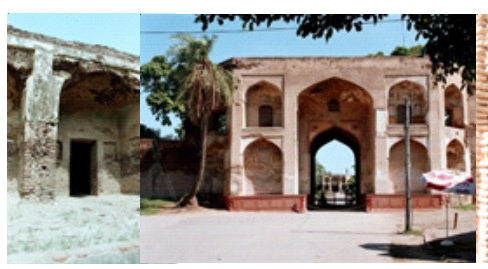

(a)

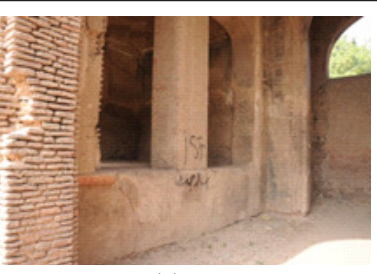

(c)
Fig. 1. Sampling locations (a) rest rooms (b) entrance gateway and (c) surrounding verandah (corridor) of the Akbari-Serai

samples used as renders. The sample 5 was collected from an under-arch wall of the corridor representing the plaster layer, sample 6 and 7 were collected from the decorative layers of plasters.

Characterization methodology: The lime mortars and plasters were characterized using the analytical methodology which integrates the use of different techniques namely, $\mathrm{X}$ ray diffraction, SEM-EDS, optical microscopy (on polished surfaces, thin sections and insoluble residues after acid attack) and XRF analysis that enabled the evaluation of their chemical compositions and mineralogical phases ${ }^{7-9}$. The binder and aggregate ratio was determined by the dissolution of samples in dilute hydrochloric acid.

Mineralogical composition and phases were identified by using Bruker, AXS D8 Advance powder diffractometer with $\mathrm{CuK}_{\alpha}$ radiation. The patterns were obtained with a Lynxeye super speed detector, step scanning from $5-80^{\circ}$ with a count for $0.5 \mathrm{~s}$ per step in addition to thin sections studies under a petrographic polarizing microscope.

The morphologies, microstructures and chemical compositions of samples were determined by using Scanning Electron Microscope (SEM), JEOL JSM 6390 LA coupled with electron probe microanalyzer EDS (EDS, Oxford-1 NCA) on polished sample surfaces.

The complete chemical characterization (major and trace elements) was carried out with wave-length dispersive X-ray fluorescence spectrometer (WD-XRF, Axios, PANalytical) equipped with 5 diffraction crystals for ten major $\left(\mathrm{SiO}_{2}, \mathrm{TiO}_{2}\right.$, $\mathrm{Al}_{2} \mathrm{O}_{3}, \mathrm{Fe}_{2} \mathrm{O}_{3}, \mathrm{MnO}, \mathrm{MgO}, \mathrm{CaO}, \mathrm{Na}_{2} \mathrm{O}, \mathrm{K}_{2} \mathrm{O}, \mathrm{P}_{2} \mathrm{O}_{5}$ ) and 21 trace elements ( $\mathrm{S}, \mathrm{Sc}, \mathrm{V}, \mathrm{Cr}, \mathrm{Co}, \mathrm{Ni}, \mathrm{Cu}, \mathrm{Zn}, \mathrm{Ga}, \mathrm{Rb}, \mathrm{Sr}, \mathrm{Y}, \mathrm{Zr}$, $\mathrm{Nb}, \mathrm{Ba}, \mathrm{La}, \mathrm{Ce}, \mathrm{Nd}, \mathrm{Pb}, \mathrm{Th}, \mathrm{U})$.

\section{RESULTS AND DISCUSSION}

Macroscopic examination (Table-1) of dull white coloured masonry mortar samples (samples 1 and 2) showed that the aggregates are composed mainly of crushed brick pieces and fragmented nodules which are locally known as Kankar with a fraction of quartz-sand as shown in Fig. $2 a^{7,10}$. The similar aggregates were found in the other two mortar samples (samples 3 and 4) used as render but with moderate sizes in addition to the brick kiln slag (Fig. 2b1). The plaster sample (sample 5) indicated fine size fragments of Kankar, milled brick powder (locally known as Surkhi) and quartz sand (Fig. 2b2) with different ratio as compared to mortar samples. The decorative plaster-off white coloured samples (samples 6 and 7) showed very fine size quartz-sand as an aggregate in small proportion (Fig. 2b3) with considerably higher amounts of lime binder. Fibrous material was observed in all the samples except the decorative plaster samples indicated its use as an additive for improving mortars bonding strength.
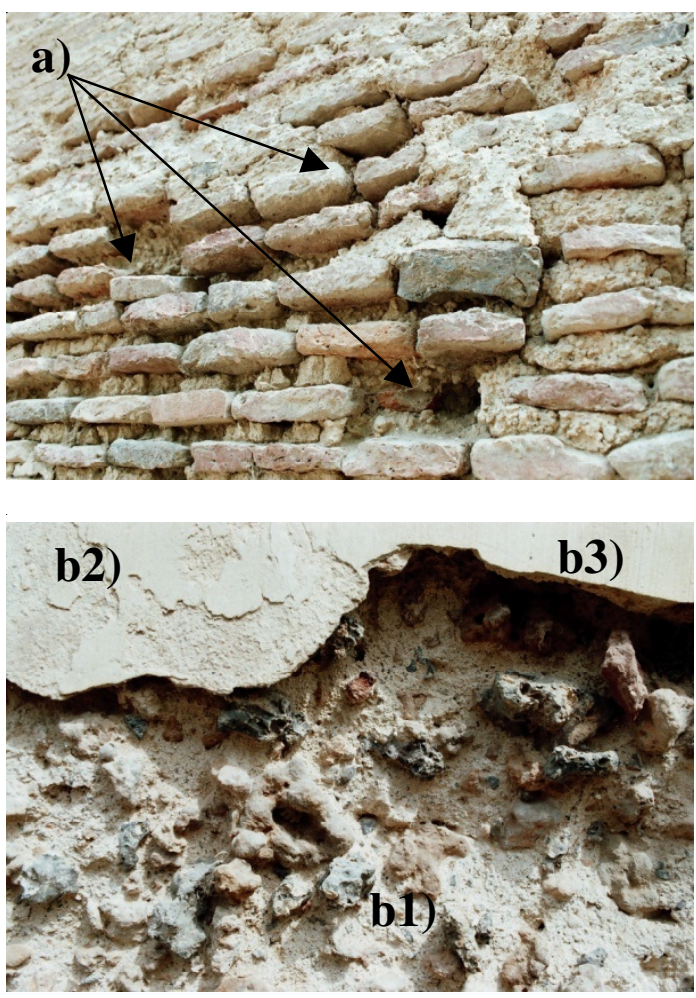

Fig. 2. Visual and macroscopic studies of (a) mortars (b1) renders (b2) plaster and (b3) decorative plaster

Optical microscopy of investigated mortars and plasters (on thin sections and cross sections) indicated calcitic lime binder with different proportions of aggregates (Table-1) based on their function in the masonry unit as also determined by acid digestion ${ }^{2,6,11}$. The burnt lime was usually slaked with water as shown in equation below ${ }^{11-13}$ :

$$
\mathrm{CaO}+\mathrm{H}_{2} \mathrm{O} \rightarrow \mathrm{Ca}(\mathrm{OH})_{2}+\text { heat }
$$

The observed largest fraction of the aggregates consists of Kankar-carbonate and crushed brick pieces with sand (as fine aggregate) and jute fibers ${ }^{13}$. This observation indicated

\begin{tabular}{cllcc} 
& & \multicolumn{2}{c}{ TABLE-1 } \\
& & \multicolumn{1}{c}{ DESCRIPTION OF THE AKBARI-SERAI SAMPLES } \\
\hline Sample & Masonry Function & \multicolumn{1}{c}{ Location } & Binder & \multicolumn{1}{c}{ Aggregate (coarse and fine) } \\
\hline 1 & Filler & Restrooms & Lime & Brick, Kankar, sand \\
2 & Filler & Restrooms & Lime & Brick, Kankar, sand \\
3 & Render & External wall & Lime & Brick, Kankar, Sand, Brick Kiln Slag \\
4 & Render & Inner wall & Lime & Brick, Kankar, Sand, Brick Kiln Slag \\
5 & Plaster & Arch wall-corridor & Lime & Brick, Kankar, Sand \\
6 & Decorative Plaster & Exterior wall rear facade & Lime & Sand \\
7 & Decorative Plaster & Inner wall of rooms & Lime & Sand \\
\hline
\end{tabular}


use of locally available kankar (carbonate source for lime), extracted from the B-horizon of soil profile in addition to the high level river terraces around the cities of Lahore and Kasur. The subangular to subrounded quartz grains embedded in the binder content are mainly silt sized to very fine sand sized as observed in the thin sections. The petrographic studies showed that the sand used in these mortars correlates mineralogically with Ravi sand which is the local source within the vicinity. The fibrous material was also observed to be the locally available jute fiber ${ }^{14,15}$.

The XRD results also showed that the mortars and plasters (whole fraction) are essentially composed of carbonate (calcite) and siliceous aggregates confirming the optical observations ${ }^{14,15}$. The presence of gypsum and halite in the plaster samples indicated its later development as a result of chemical deterioration on the exposed historic fabric ${ }^{16-20}$ as under further investigation by SEM-EDS.

The chemical composition (for major and trace elements) was obtained by XRF spectrometry. The chemical data clearly distinguished the samples as shown in Figs. 3-5.

The mortar samples (sample 1 and 2) were composed of $65-66 \%$ calcite and $22 \%$ silica with $5 \%$ alumina. The iron content is $2-3 \%$ with the soda and potash values range from $0.7-1.1 \%$ while the magnesia content is ca. $1 \%$.

The render samples (sample 3 and 4) were composed of $47 \%$ calcite with higher amount of silica, alumina and iron (36, 6-7 and 2.5-3.5\%). The soda and potash values range from 1.6-1.7\% while the magnesia content is ca. $2.3 \%$ corresponding to the higher aggregate content ${ }^{21,22}$.

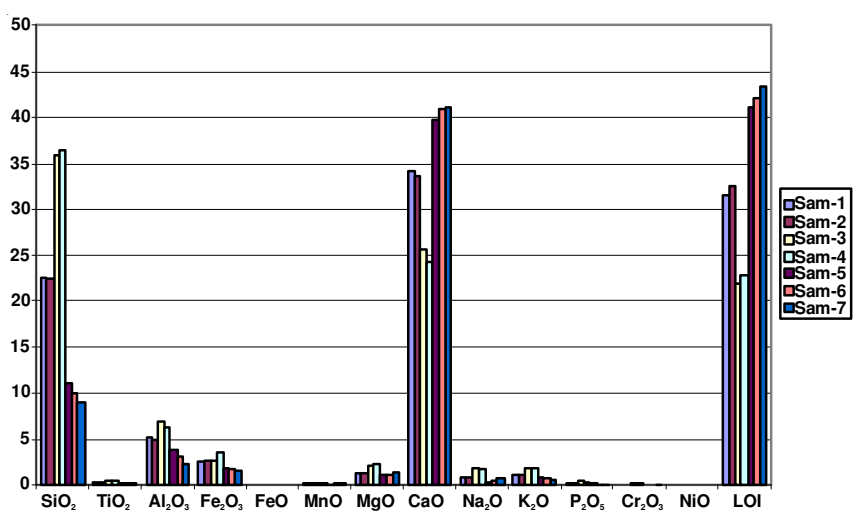

Fig. 3. Chemical composition for major elements of samples determined from XRF analysis

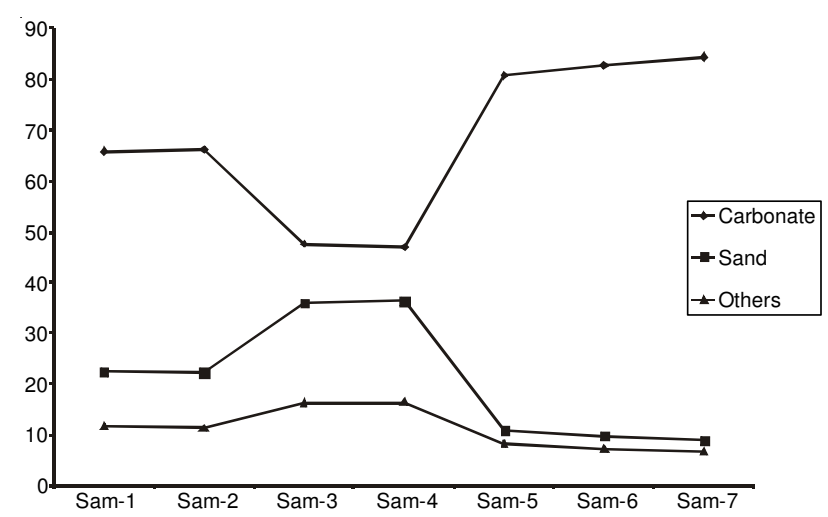

Fig. 4. Simplified chemical composition of samples (wt \%)

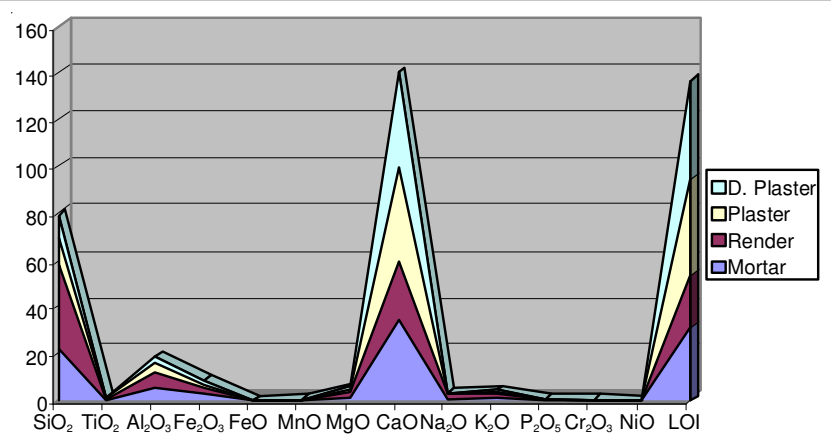

Fig. 5. Comparative chemical composition (major elements) for mortar, render, plaster and decorative plaster samples

The plaster sample (sample 5) is rich in calcite ( $\mathrm{ca} .81$ $\%$ ), has a low silica content of $c a .11 \%$ and alumina $3.7 \%$. Similarly, the iron content is $1.6 \%$, soda and potash range from $0.2-0.7 \%$ and magnesia $1 \%$.

The decorative plaster contains $82-85 \%$ and $c a .10 \%$ silica. Alumina ranges from 2-3\% with variable amounts of soda $(0.4-0.6 \%)$ and potash $(0.5-0.7 \%)$. The hematite content was $1.5 \%$. The binder aggregate ratio of plaster samples (Table-1) were further elaborated by the chemical characterization.

The simplified composition (carbonates, sand and others) of three types of samples was plotted as shown in Fig. 4 to develop the trend lines ${ }^{2,23}$. It clearly depicts the carbonate content of mortars was higher than renders but lower then plasters. Similarly the siliceous content of mortars was lower than renders but higher than plasters ${ }^{23,24}$. The results clearly depicted the varying binder aggregate content (Fig. 5) for all samples related to their structural position ${ }^{25}$. This difference of binder aggregate ratio which can only be determined with high accuracy by the chemical analysis like XRF is the key step in developing the compatible mortars for future conservation works.

The chemical nature of trace elements (Fig. 6) suggested the use of same raw materials were employed in the manufacture of all the four studied masonry types ${ }^{26}$.

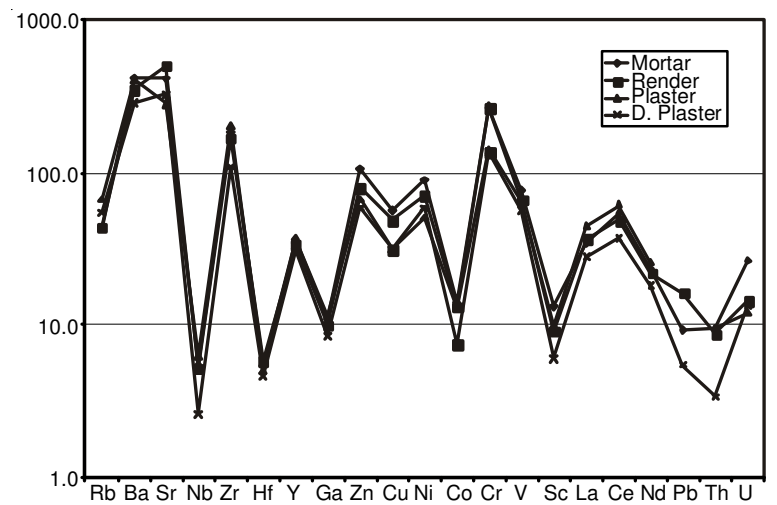

Fig. 6. Comparative chemical composition (trace elements) for mortar, render, plaster and decorative plaster samples

Scanning electron micrographs (Fig. 7) exhibits a microstructure typical of lime binder (Fig. 7a) with little small calcium carbonate crystals partially jellified (CSH formations) as in hydraulic limes ${ }^{27,28}$.

$$
\mathrm{Ca}(\mathrm{OH})_{2}+\mathrm{CO}_{2} \rightarrow \mathrm{CaCO}_{3}+\mathrm{H}_{2} \mathrm{O}
$$

Slaked lime (soft) $\rightarrow$ Carbonated lime (hard)

$$
\mathrm{Ca}(\mathrm{OH})_{2}+\mathrm{SiO}_{2} \rightarrow \mathrm{CaOSi}_{2} \cdot \mathrm{H}_{2} \mathrm{O}
$$



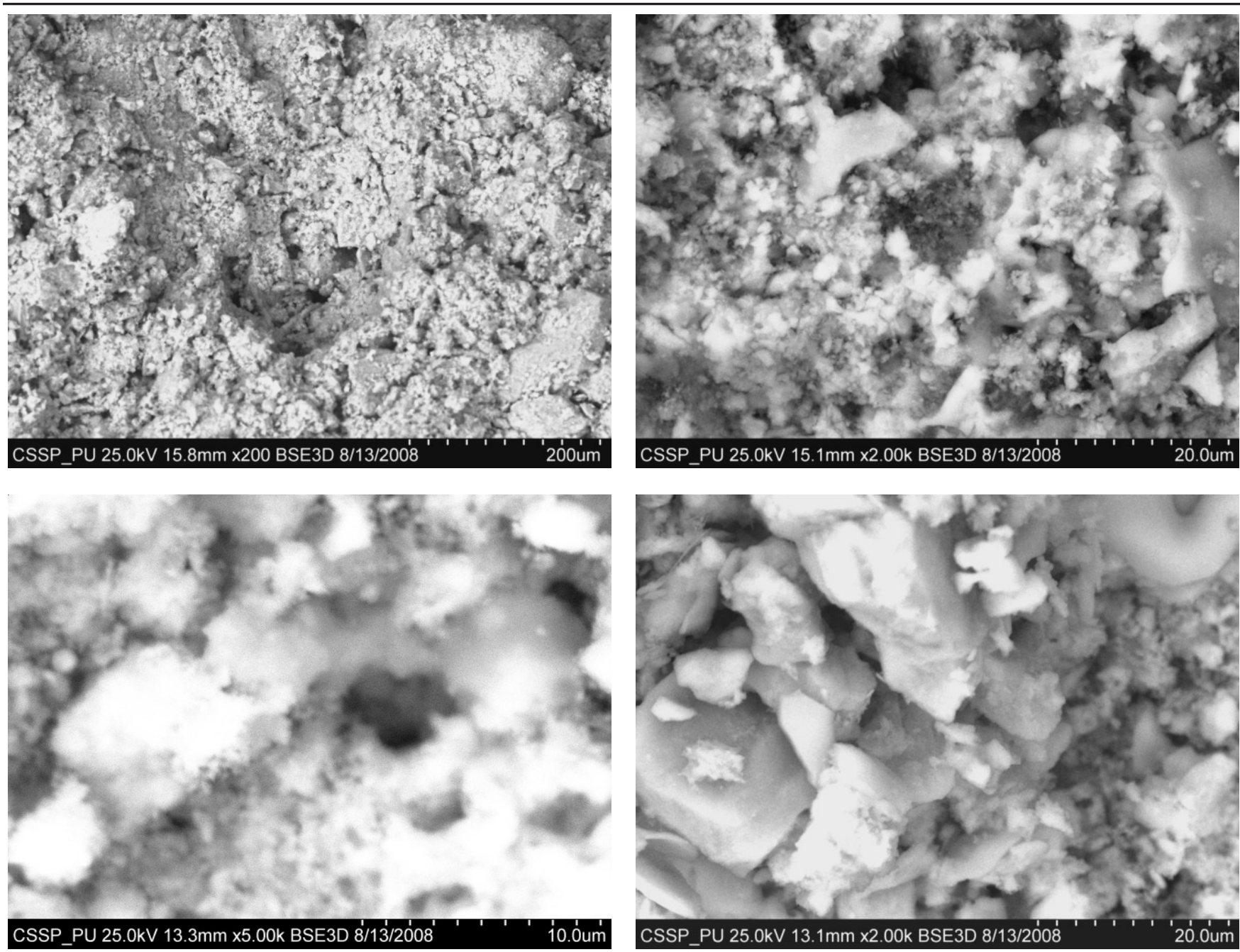

Fig. 7. Scanning electron micrographs (a) general aspect of the microstructure of the lime binder (b) embedded quartz grain in the paste (c) microbiological contaminations and (d) halite crystals

This further established the use of abundant limestone fragments (locally known as kankar) as the main aggregate with sand and crushed bricks, which was most likely recrystallised as fine calcite and CSH aggregates and oriented as clusters following the hydration process ${ }^{27}$ :

$$
\begin{aligned}
& \mathrm{CaO}+\mathrm{H}_{2} \mathrm{O} \rightarrow \mathrm{Ca}(\mathrm{OH})_{2} \\
& \mathrm{Ca}(\mathrm{OH})_{2}+\mathrm{CO}_{2} \rightarrow \mathrm{CaCO}_{3}+\mathrm{H}_{2} \mathrm{O} \\
& \mathrm{CaCO}_{3}+\mathrm{H}_{2} \mathrm{O} \rightarrow \mathrm{Ca}\left(\mathrm{HCO}_{3}\right)_{2} \text { (soluble) } \\
& \mathrm{Ca}\left(\mathrm{HCO}_{3}\right)_{2}+\mathrm{Ca}(\mathrm{OH})_{2} \rightarrow 2 \mathrm{CaCO}_{3}+2 \mathrm{H}_{2} \mathrm{O}
\end{aligned}
$$

The observed quartz particles were found well embedded in the binder (Fig. 7b). The measurements by SEM-EDS also clearly indicated the megascopically identified deterioration contents within the historic fabric. The biological contaminations were also found in few samples as shown in Fig. 7c. The halite crystals as shown in Fig. 7d can be attributed to the chemical alterations formed due to the deterioration of exposed historic materials which was further confirmed with $\mathrm{EDS}^{28-30}$.

\section{Conclusion}

The chemical and mineralogical characterization of 17th century Mughal mortars, renders and plaster have shown the same type of coarse (brick, kankar pieces, slag) and fine (river sand) aggregates embedded in calcitic lime binder. The varying binder aggregate ratio was found dependant on the functional aspect of the masonry unit. The chemical composition (major and trace) indicated locally available raw materials for the construction of these historic monuments. The scanning electron microscopy with EDS chemical analysis also highlighted the chemical alterations developed due to the interaction with the surrounding environment. This characterization would help in preparing the compatible materials for the restoration with similar proportions and possibly the same materials (as locally available materials were used in the original construction) to avoid incompatible deformations with the historic materials.

\section{REFERENCES}

1. J. Ashurt and N. Ashurt, Mortars, Plasters and Renders, Practical Building Conservation, English Heritage Technical Handbook 3, Gower Technical Press, Vol. 3 (1989).

2. A.M.P. Carneiro and M. Lima da Costa, Chemical and Mineralogical Characterization of Mortars from the Bolonha Palace in the City of Belém, State of Pará-Brasil, Proc. of the 3rd International Seminar on Possibilties of Numerical and Experimental Techniques: Historical Constructions, Portugal, p. 331 (2001).

3. S. Gulzar, M.Sc Thesis, Environmental Effects on Cultural Heritage: Shahdara Complex-Lahore, University of the Punjab, Lahore, pp. 6280 (2004).

4. A. Rehmani and M.A.Thesis, History and Architecture of Mughal Monuments at Shahdara, University of the Punjab, Lahore pp. 12-35 (1976). 
5. M.S. Khan, M. Ahmad and M.A. Khan, Lahore Museum Bull., 13, 115 (2000).

6. J. Elsen, Cem. Concr. Res., 36, 1416 (2006).

7. B. Fielden, Guidelines for Conservation- A Technical Manual, The Indian National Trust for Arts and Cultural Heritage, Delhi, pp. 55-56 (1989).

8. G. Chiari, G. Torraca and M.L. Santarelli, Standards for Preservation and Rehabilitation, ASTM 1996; STP 1258, pp. 275-278 (1996).

9. C. Genestar, C. Pons and A. Mas, Anal. Chim. Acta, 557, 373 (2006).

10. M. Aslam, M.L. Tabasso, P.L. Bian Chatti and A.E. Charole, Studies of Lime Plasters and Mortars of the Taj Mahal, 8th Triennial Meeting, Sydney, Preprint, Vol. 2 (1987).

11. J. Elsen, A. Brutsaet, M. Deckers and R. Brulet, Microscopical Mater. Charact., 53, 289 (2004).

12. S. Chandra, History of Architecture and Ancient Building Materials in India, India, Tech Books International (2003).

13. K. Rehyan, M.Sc. Thesis, Construction Techniques and Materials of Ottoman Period Baths in Urla-Seferihisar region, Izmir Institute of Technology (2004).

14. M.S. Khan, J. Asian Civiliz., 30, 1 (2007).

15. M.S. Khan, Protecting the Historic Property from the Effect of Environmental Degradation, Cultural Tourism Lahore \& Peshawar, UNESCO Publication, Vol. 3 (2003).

16. D. Benedetti, S. Valetti, E. Bontempi, C. Piccioli and L.E. Depero, Appl. Phys., 79(A), 341 (2004).

17. R. Castelló, P. Morillas, C. Vizcayno and J. Martín-Rodríguez, Centro de Ciencias Medioambientales, Csic, Characterization of rendering mortars on some buildings of Toledo, Spain, Third International Congress on "Science and Technology for the safeguard of Cultural Heritage in the Mediterranean Basin", Alcalá de Henares, Spain, July 9-14 (2001).
18. J.I. Alvarez, I. Navarro and P.J. García Casado, Thermochim. Acta, 365, 177 (2000).

19. J. Weber, W. Prochaska and N. Zimmermann, Mater. Charact., 60, 586 (2009).

20. H. Böke, S. Akkurt, B. Ipekoglu and E. Ugurlu, Cem. Concr. Res., 36, 1115 (2006).

21. A. Moropoulou, A. Bakolas and K. Bisbikou, J. Cult. Herit., 1, 45 (2000).

22. M.P. Riccardi, M. Lezzerinin, F. Caro, M. Franzini and B. Messiga, J. Cult. Herit., 8, 350 (2007).

23. E. Ugurlu and H. Boke, Const. Build. Mater., 23, 2442 (2009).

24. B. Schouenborg, J.E. Lindqvist, M. Sandström, K. Sandin and E. Sidmar, Analysis of Old Lime Plaster and Mortar from Southern SwedenA Contribution to the Nordic Seminar of Building Limes, Swedish National Testing and Research Institute, Building Technology, Special Report 1993, p. 34 (1993).

25. S. Ullah, Composition and Properties of Historic Lime Mortars, 16th International Congress on Deterioration and Conservation of Stones, Proceedings Actes, p. 484 (1995).

26. E.M. Chamot and C.W. Mason, Handbook of Chemical Microscopychemical Methods and Inorganic Qualitative Analysis, Vol. 2, John Wiley and Sons Inc., New York (1946); Republished by McCrone Research Institute, Chicago, IL (1989).

27. M. Radonjic, K.R. Hallam, G.C. Allen and R. Hayward, Mechanism of carbonation in lime-based mortars. Proc 8th Euroseminar on Microscopy Applied to Building Materials. Athens; pp. 465-75 (2001).

28. M.S. Vast, Bull. Architect. Survey India, 6, 93 (1949).

29. S. Pavía and S. Caro, Const. Build. Mater., 22, 1807 (2008).

30. G. Mertens, J. Elsen, R. Brulet, A. Brutsaert and M. Deckers, Mater. Charact., 60, 580 (2009). 